Article type $\quad$ : 3 Original Article - Australia, Japan, SE Asia (CEN)

\title{
Younger age a risk factor for regrowth and recurrence of non- functioning pituitary macroadenomas: Results from a single Australian centre.
}

Watts $\mathrm{AK}^{1}$ MPH TM, Easwaran $\mathrm{A}^{2}$, McNeill $\mathrm{P}^{3}$, Wang $\mathrm{YY}^{3}$, Inder $\mathrm{WJ}^{4,5}$, Caputo $\mathrm{C}^{1}$

Departments of Endocrinology \& Diabetes, St Vincent's Hospital Melbourne, Victoria, Australia ${ }^{1}$,

Department of Biostatistics, St Vincent's Hospital Melbourne, Victoria, Australia ${ }^{2}$

Department of Neurosurgery, St Vincent's Hospital Melbourne, Victoria, Australia ${ }^{3}$,

Department of Diabetes \& Endocrinology, Princess Alexandra Hospital, Brisbane,

Queensland, Australia ${ }^{4}$,

Faculty of Medicine, University of Queensland, Brisbane, Queensland, Australia ${ }^{5,}$

Correspondence:

Carmela Caputo

Department of Endocrinology \& Diabetes

St Vincent's Hospital

Level 4 Daly Wing, 35 Victoria Parade, Fitzroy VIC 3065 Australia

carmela.caputo@svha.org.au

Phone: +61392313590

Fax: +61392313590

This is the author manuscript accepted for publication and has undergone full peer review but has not been through the copyediting, typesetting, pagination and proofreading process, which may lead to differences between this version and the Version of Record. Please cite this article as doi: $10.1111 /$ cen. 13365

This article is protected by copyright. All rights reserved 
Short title: Regrowth of radiotherapy-naïve non-functioning pituitary adenomas

MeSH terms: pituitary macroadenoma, regrowth, recurrence

Acknowledgements: nothing to declare

Portions of this work were presented in poster form at the Endocrine Society of Australia Annual Scientific Meeting, Adelaide, August 242015 and in oral form at the Endocrine Society of Australia Annual Scientific Meeting, Gold Coast August 242016

Word count:

Abstract: 244

Body of text: 3477
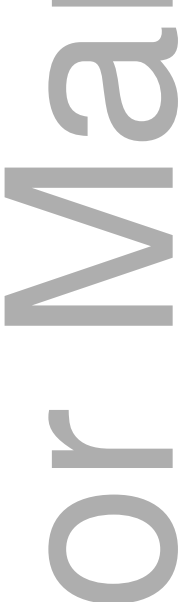

\section{Abstract}

Objective: The natural history of non-functioning pituitary macroadenomas (NFPMA) after surgical resection is variable, with guidelines unable to define the duration of radiological follow up. In this first Australian series, we identify risk factors for regrowth/recurrence of NFPMA to assist with guiding recommendations for long-term follow-up.

Design: Retrospective analysis of all radiotherapy naïve cases with NFPMA resected between $1995-2013$.

Patients: One hundred and twenty-three cases had both $\geq 2$ post-operative scans and $\geq 12$ 
months follow up.

Measurements: Regrowth was defined as any sustained increase in diameter of residual adenoma or recurrence as any new adenoma occurring post complete resection on serial pituitary MRI.

Results: Median follow up time was 48 months (IQR 31-86). Overall regrowth/recurrence occurred in $29 \%$ (36/123). Regrowth occurred in $40 \%$ (30/76) at a median time of 44.5 months (IQR 22-80) compared to recurrence of $12.5 \%(6 / 48)(\mathrm{p}=0.003)$, occurring at a median time of 48 months (IQR 12-96) ( $\mathrm{p}=0.7)$. Further treatment was required in $66.7 \%$ and $56.7 \%$ respectively $(\mathrm{p}=1.0)$. Risk factors for regrowth/recurrence by multivariate analysis were presence of residual disease and younger age at presentation. The longest time for regrowth was 168 months (14 years), and recurrence 156 months (13 years).

Conclusions: Presence of post-operative residual adenoma and younger age at presentation are the main predictors of regrowth/recurrence in NFPMA. Long-term serial imaging is required to detect regrowth and recurrence in younger patients and those with residual disease. Most regrowth/recurrences will occur within 10 years of follow up.

\section{Introduction}

Trans-sphenoidal surgery is the treatment of choice for non-functioning pituitary macroadenomas (NFPMA), which exhibit symptoms of mass effect including visual disturbance, headache and impaired pituitary hormone function. The natural history of most un-operated NFPMA is to grow over time, gradually exerting mass effect on surrounding structures $^{1}$. The long-term outcome of NFPMA following surgery has been considered unclear, with varying rates of regrowth and recurrences from data across the world. However, data are consistent that the presence of residual disease is a strong risk factor for regrowth. What remain poorly defined are other risk factors for regrowth/recurrence, optimal management of residual disease and optimal duration of long-term radiological surveillance ${ }^{2}$, 3

Historically cases with residual disease were treated with post-operative radiotherapy to prevent regrowth. This practice developed due to post-operative regrowth rates of up to $75 \%$ seen when resection was performed via the trans-cranial approach ${ }^{4}$. Some authors ${ }^{5-7}$, including a most recent guideline ${ }^{2}$, continue to advocate this practice for those with residual disease. Post-operative radiotherapy is very effective at reducing regrowth rates $^{8}$ but there is an increased risk of de novo pituitary insufficiency, visual field deficits, cognitive 
dysfunction, cerebrovascular disease and possibly secondary intracranial tumours ${ }^{9}$. More recently, radiotherapy has been targeted to those considered to be at high risk of regrowth or recurrence, although what defines "high risk" is not well understood. Many series have documented the regrowth/recurrence rate for a subset of patients who did not receive postoperative radiotherapy as they were deemed low risk, introducing a significant selection bias ${ }^{8}$ 10-12. These studies of low risk populations report recurrence free survival of $82-90 \%$ at 5 years and $56 \%$ at 10 years ${ }^{11,12}$. Studies documenting unselected radiotherapy naïve cases report 5-year recurrence free survival rates of $39-77 \%^{5,7,13,14}$.

The optimal duration of radiological follow up of operated NFPMA remains poorly defined, with a recent systematic review and guideline being unable to conclude the duration of time or frequency of follow up for those with or without residual disease, nor those given radiotherapy ${ }^{3}$.

We describe surgical outcomes and regrowth rate of NFPMA from a single Australian centre and identify risk factors that may predict regrowth/recurrence, to assist with planning of longterm radiological follow up. At our centre, secondary interventions such as post-operative radiotherapy or further surgery are reserved until regrowth or recurrence is demonstrated on radiological follow up; this decision made by consensus opinion of the pituitary multidisciplinary team (MDT). This is the first published series from a single Australian centre.

\section{Methods}

All cases who underwent initial pituitary surgery for NFPMA between April 1995 and December 2013 were reviewed. Ethics approval was obtained from the local Human Research Ethics Committee. Diagnosis of NFPMA was based on the presence of a pituitary adenoma $\geq 1 \mathrm{~cm}$ in maximal diameter without biochemical evidence of hormonal hypersecretion confirmed by histological and immunohistochemical assessment.

Review of the medical histories was undertaken to obtain clinical, hormonal, ophthalmologic and radiological details. Visual fields were defined as normal or abnormal based on computerized visual field testing. Multiple hormone deficiency (MHD) was defined by the hypofunction of at least 2 individual hormone axes. Details and definitions of hormone deficiencies have been previously described ${ }^{15}$. 
Post-operative pituitary imaging was performed at 3 and 12 months and then annually or as clinically indicated. All cases were followed with serial MRI pituitary except four who had CT due to MRI contraindications. Pre- and post-contrast images were obtained. Scans were reported by different radiologists throughout the follow up period but also reviewed by the primary neurosurgeon with the multidisciplinary team of endocrinologists and radiation oncologists who reviewed the case notes and imaging for each patient as part of routine follow up.

Initial adenoma was classified by Hardy classification and measured by the largest diameter in millimetres (mm). Operative resection was classified as complete or incomplete based on the presence of adenoma remnant on the first post-operative scan. Cases with regrowth or recurrence were treated on an individual basis with a combination of repeat surgery, radiotherapy or close observation, as recommended by the MDT.

Recurrence was defined as any new radiologically detected pituitary adenoma after initial complete resection. Regrowth was defined as a sustained increase in size of residual adenoma tissue in any dimension $\geq 2 \mathrm{~mm}$ detected by the reporting radiologist and confirmed by the MDT compared to the residual adenoma measured on the baseline post-operative scan.

\section{Statistical analysis}

Results are expressed as mean \pm standard deviation (SD) for parametric variables and median, interquartile range for non-parametric variables. Categorical variables were analysed using contingency tables and Fisher's exact test. Continuous variables were analysed using the unpaired t test. Univariate and multivariate analysis were used for risk factors of regrowth/recurrence. Statistical significance was set at $\mathrm{p}<0.05$, data was analysed using STATA 11.0; StataCorp, TX, USA.

Kaplan Meier curves were generated to describe total time at risk. Lifetables were used to determine 5 and 10 year survival rates. Log rank tests and univariate Cox regression was used to compare the survival rates of each variable. Based on univariate analysis, residual size and location, immunohistochemical staining, apoplexy and surgeon were excluded from multivariate analysis. Initial adenoma size was excluded from the multivariable model due to the number of missing observations. Age was analysed by quintiles with 41 and under being the youngest age group. This was included in the model as a binary variable (41 and under 
versus $>41$ ), however similar results were produced if age was used as a continuous variable. Given the increased regrowth/recurrence likely to be seen with longer duration of follow up, outcomes were adjusted for follow up duration in the current study.

\section{Results}

A total of 177 (97 male) consecutive operated NFPMA cases were identified. The median age at diagnosis was 57 years (IQR 45 - 69) (Table 1). Three (1.7\%) had immediate postoperative radiotherapy due to large post-operative remnant; these were excluded from the regrowth/recurrence analysis. In total, 123 cases $(69.5 \%)$ had more than 12 months follow up and at least two post-operative scans.

\section{Mode of presentation and hormonal status}

$61 \%(108 / 177)$ of cases presented due to symptoms of mass effect or hormonal dysfunction, $10.7 \%(\mathrm{n}=19)$ presented with apoplexy, the adenoma was discovered incidentally on imaging performed for other reasons in the remaining 28.2\% $(n=50$, Table 1). 69\% $(118 / 177)$ of cases reported visual disturbance at baseline, bitemporal hemianopia in 33.3\% (57/117). Postoperative visual improvement occurred in $88 \%$ (73/88).

Mean pre-operative prolactin concentration was $639 \pm 528 \mathrm{mIU} / \mathrm{L}$ (range $14-3303 \mathrm{mIU} / \mathrm{L}$ ). Prolactin was $>2000 \mathrm{mIU} / \mathrm{L}$ in $2.7 \%(4 / 148)$ cases. Over $58 \%$ of cases had at least one axis deficiency pre-operatively, and more than one third had MHD. At 6 months post-operatively, $38 \%$ had MHD (Table 1).

\section{Surgery}

Surgery was performed by the primary surgeon $(\mathrm{P} \mathrm{McN})$ in $72 \%(127 / 177)$ of cases; the remainder being performed by one of five other neurosurgeons. The trans-sphenoidal (microscopic) technique was utilised in 161 (91\%), trans-sphenoidal (endoscopic) in 15 (8\%) and one case underwent craniotomy (1\%). The majority, $88.1 \%(156 / 177)$ underwent 1 procedure, $9.6 \% 2$ procedures and $2.3 \% 3$ procedures during the follow up period (Table 1).

\section{Post-operative complications}

One or more post-operative complications occurred in $32.2 \%(57 / 177)$ of cases at first surgery (Table 1). This included the syndrome of inappropriate anti-diuretic hormone (SIADH) $8 \%$ 
(14), transient DI 15.3\% (27), permanent DI 6.8\% (12), CSF leak 4.5\% (8) and cardiac events $1.1 \%$ (2). One patient needed removal of retained nasal packs $(0.6 \%)$. There were 2 cases of significant post-operative bleeding; 1 case on warfarin, who had a pre-operative INR of 1.2 and the other case who required urgent surgery due to pituitary apoplexy post coronary artery bypass grafting (CABG) treated with tirofiban and intravenous heparin. There were $3(1.7 \%)$ cases of cerebrospinal fluid infection. The primary surgeon had a lower complication rate compared to the others combined $(\mathrm{p}=0.04)$, which was more marked if transient DI was excluded from the analysis $(\mathrm{p}=0.02)$.

There were 10 deaths during follow up. One occurred within 3 months of operation in a 52 year old female who developed pituitary apoplexy whilst thrombocytopenic in the setting of chemotherapy for acute myeloid leukemia. She died one week post operation due to ventricular fibrillation during neutropaenic sepsis. The remaining 9 deaths occurred between 6 months and 9 years of follow up: cause of death was unrelated malignancy (3 cases), cerebrovascular accident ( 2 cases) or unknown causes (4 cases). Median age of death of cases was 79 years (IQR $68.5-82.5$ ).

Immunohistochemistry was available for 174 adenomas. The majority, $46 \%$, were null cell adenomas and $6.3 \%$ were silent ACTH adenomas (Table 1).

\section{Regrowth/Recurrence}

Analysis of adenoma regrowth or recurrence was undertaken on 123 cases. Of the original cohort (177), 54 cases were excluded; 34 had less than 12 months follow up at our centre, 17 failed to attend their $2^{\text {nd }}$ post-operative scan and 3 cases underwent immediate post-operative radiotherapy. 9 cases underwent repeat surgery due to stable large post-operative residual; these cases were not classified as having regrowth. Follow up was until regrowth/recurrence was detected or most recent recorded MRI. Median follow up time was 48 months (IQR 31 86). There was a similar duration of follow up for those with and without regrowth/recurrence.

Residual adenoma was demonstrated in $61 \%(76 / 123)$ of cases on the first post-operative scan, with 40\% (30/76) located intrasellar, 8\% (6/76) suprasellar and 49\% (37/76) involving one or both cavernous sinuses. The location of residual adenoma, was unrecorded in 2/76 
cases. Those where the initial scan was unclear as to the presence of residual adenoma were classified according to the result of the $2^{\text {nd }}$ post-operative scan.

The overall rate of regrowth and recurrence was $29 \%$ (36/123). Regrowth of adenoma was observed in $40 \%$ (30/76) at a median time of 44.5 months (IQR 22-80) compared to recurrence of $12.5 \%(6 / 48)(\mathrm{p}=0.003)$, occurring at a median time of 48 months (IQR 12-96). There was no significant difference in the time to regrowth versus recurrence $(p=0.7$, Table 2). Two cases of adenoma growth were detected at $>10$ years follow-up: a regrowth at 168 months (14 years) and a recurrence at 156 months (13.3 years).

Overall 5 and 10-year progression-free survival rates were $77 \%$ and $50 \%$ respectively. Progression-free survival amongst the cohort with no post-operative residual adenoma seen on initial scan was $92 \%$ at 5 years and $77 \%$ at 10 years compared to $67 \%$ and $38 \%$ in those with post-operative residual adenoma $(\mathrm{p}=0.07$ and $\mathrm{p}=0.007$ respectively, Table 2 and Figure 1).

In the 36 cases with regrowth or recurrence, intervention was required in 21/36 (58\%), consisting of repeat surgery in $33 \%(n=7)$, radiotherapy in $38 \%(n=8)$ and both modalities in $29 \%(n=6)$. The remaining $42 \%(n=15)$ cases were observed, with further serial imaging planned. Rates of treatment and observation were similar between those with regrowth or recurrence (Table 2).

Significant factors associated with regrowth/recurrence after multivariate analysis were presence of post-operative residual adenoma $(\mathrm{p}=0.0008)$ and younger age at presentation $(p=0.0001)$. Univariate analysis indicated that there was a regrowth rate reduction of approximately $3 \%$ for every year older a subject was at presentation. The rate of regrowth remained 4.2 times higher in individuals 41 and younger compared to those aged over 41 , after accounting for gender and the presence of residual disease (Figure 2). The rate of regrowth remained 4.8 times greater than recurrence, after accounting for gender and age (Figure 1).

Larger baseline adenoma size was a predictor of regrowth/recurrence ( $\mathrm{p}=0.05$, Table 3$)$ however was not included in the multivariate analysis as there were 19 cases where these data 
were missing. However, this association may still be significant given the likelihood that the cause for the missing data was random.

On univariate analysis, males with residual disease were significantly more likely to regrow than females with residual disease $(52.5 \%$ vs $25.7 \%$, $\mathrm{p}=0.03)$, but the effect of gender was not significant when examining regrowth and recurrence combined $(\mathrm{p}=1.00)$ (Table 2). There was no association with risk of regrowth/recurrence and presence of extra sellar adenoma at baseline ( $\mathrm{p}=0.6)$, extra sellar residual $(\mathrm{p}=1.0)$ (Table 3$)$, size of residual adenoma $(\mathrm{p}=0.2)$, nor presentation with apoplexy $(\mathrm{p}=0.3)$ (Table 3). Regrowth/recurrence requiring treatment was strongly predicted by extra sellar adenoma at baseline $(\mathrm{p}<0.01)$, but not extra sellar residual $(\mathrm{p}=0.6)$ nor apoplexy $(\mathrm{p}=1.0)$.

Adenomas with invasion into one or more cavernous sinuses were less likely to be completely resected $(\mathrm{p}=0.01)$, however this did not predict regrowth or lack thereof. There was no difference between surgeons in terms of risk of residual adenoma $(\mathrm{p}=0.5)$ nor post-operative regrowth/recurrence $(\mathrm{p}=0.10)$.

There were 13 cases with apoplexy. None of the 8 apoplexy cases without residual disease had recurrence, however, regrowth was observed in 2 out of 5 with apoplexy who had residual adenoma.

Immunostaining for ACTH was not associated with increased risk of regrowth/recurrence $(\mathrm{p}=0.76)$, although numbers were small.

\section{Discussion}

In this first Australian series of operated NFPMA, we have described the natural history of regrowth/recurrence in an unselected cohort of radiotherapy naïve cases. The two major risk factors are the presence of residual disease and younger age at diagnosis. Other studies have demonstrated that residual disease strongly predicts adenoma regrowth ${ }^{5,8,10}$. An association between younger patient age and risk of regrowth/recurrence has been shown by some investigators $5,7,16,17$, although not all ${ }^{6,11,13,18}$. 
Even in expert hands, the presence of residual disease is a frequent finding post-surgery.

Single centre series of NFPMA throughout the world report rates of residual disease between $54-80 \%$ cases, similar to our finding of $61 \%$, 7, 13, 14, 16, 18, 19 . An exceptionally low rate of residual disease of $32 \%$ was achieved by a recent Korean group using the traditional microscopic technique ${ }^{6}$.

There is inconsistency in the rate of regrowth and recurrence in radiotherapy naïve series throughout the world literature. Series from Europe ${ }^{5,8,16}$, Korea $^{6}$ and Israel ${ }^{14}$ report regrowth rates between 42-59\% over mean of 4-6 years of follow up and recurrences in $6.9-20 \%$. Notably, the lowest rates of regrowth/recurrence observed over long follow up periods occurred in an Irish ${ }^{7}$, Dutch $^{19}$ and North American series ${ }^{18}$, with regrowth of 33.5\%, 14\% and $28 \%$, and recurrences of $0 \%(0 / 26), 0 \%(0 / 27)$ and $5.2 \%(13 / 248)$ respectively. A French series by Sotos-Ares et $\mathrm{al}^{13}$, also reported low rates, but this could be explained by a shorter follow up of period of mean 2.3 years (38.2\% regrowth and $0 \%(0 / 7)$ recurrence).

Invasive nature of adenoma at baseline is a predictor of regrowth/recurrence in some studies ${ }^{14}$, 17, 20. This may be the case as those with larger, more invasive and possibly more aggressive adenomas at baseline are likely to have a more extensive remnant. Unlike the study by Greenman et al. ${ }^{14}$, pre-operative adenoma invasion into the cavernous sinuses did not predict regrowth/recurrence in the present study, however it was associated with risk of postoperative residual adenoma. Given post-operative remnant is a well described risk factor for regrowth $^{5,8,10}$, the association in those with invasive adenoma at baseline may, therefore, more accurately reflect the likelihood of residual disease in these subjects.

Some authors argue that the volume $e^{7,13}$ or location ${ }^{7,} 14$ of remnant predicts adenoma regrowth. Extent and location of remnant may be a marker of an aggressively growing adenoma, which is more likely to regrow. However, in our series neither size (measured as maximal adenoma diameter) nor location of residual adenoma were predictors of regrowth/recurrence. Our findings would suggest that having any residual, irrespective of location, has the propensity for regrowth.

In our series, the majority of surgeries were undertaken by one surgeon. We did not find any difference in the prevalence of residual disease, nor the risk of regrowth/ recurrence between the primary surgeon compared to the other surgeons. 
In our series, younger age of diagnosis was a significant factor predicting regrowth/recurrence. We demonstrated a 3\% increase in relative risk of regrowth/recurrence for every year younger a patient was at the time of presentation. Meaning there was a lower risk of regrowth/recurrence in patients presenting with NFPMA later in life. The older a patient was at time of presentation, the less likely they were to suffer regrowth/recurrence. This observation allows clinicians greater confidence when electing to decrease or cease surveillance in the elderly. Four European studies have found younger age to be a risk factor ${ }^{5}$, 7, 16, 17, but this was not substantiated in the Korean ${ }^{6}$, North American ${ }^{18}$, nor two European series $^{11,13}$

On univariate analysis, we found that amongst those with residual adenoma, males were more likely to exhibit regrowth than females. This association has not found by others, and contrary to our findings, Park and colleagues found an increased risk of regrowth in female cases on univariate analysis ${ }^{21}$.

A previous study showed immunohistochemical staining for ACTH was associated with more aggressive recurrence but not increased recurrence rates ${ }^{22}$. In contrast, a more recent and larger study has shown a sub-group of silent corticotroph adenomas do have a higher recurrence rate $^{23}$. We did not demonstrate an association between ACTH staining and propensity for regrowth/recurrence, however numbers were small. Mixed staining was not associated with any increase in regrowth/recurrence, in contrast to another series which reported an increased propensity for regrowth/recurrence in those with mixed staining and those who did not stain positive for gonadotrophins ${ }^{20}$.

In this study we have not reported proliferative marker Ki67 expression or p53 immunoreactivity, as these have only been utilised in recent years at our centre. The 2004 World Health Organisation classification of atypical pituitary adenoma includes invasive growth, increased mitotic activity, high p53 immunoreactivity and Ki67 labelling index above $3 \%$. Atypical adenomas can constitute up to $15 \%$ of pituitary adenoma ${ }^{24}$, however the utility of these markers is still unclear in typical pituitary adenomas ${ }^{25}$.

Pituitary apoplexy may have a lower risk of regrowth/recurrence possibly relating to apoplexy predicting the absence of residual adenoma ${ }^{12,17}$. Although not reaching statistical significance 
due to small numbers, our data support that the presence of any residual disease following apoplexy remains a risk factor for regrowth. This is also supported by data from Oxford, where regrowth occurred in 3 of 27 cases of apoplexy, with all 3 having residual disease ${ }^{26}$.

A pertinent clinical question posed by Reddy et al. is when to stop imaging those with operated NFPMA who are not irradiated ${ }^{5}$. The authors were unable to define a time point from their study but adenoma growth occurred in cases after 10 years. They therefore concluded that imaging should continue indefinitely and recommended that early irradiation should be considered in those with post-operative extrasellar adenoma ${ }^{5}$. The French Endocrine Society's recent consensus paper addresses the frequency of follow-up imaging, suggesting annual imaging for the first 5 years then every 2-3 years in a case dependent manner in those with residual disease ${ }^{27}$. In those without residual disease, imaging should occur annually for the first 5 years, then at 7, 10, 15 years: before ceasing. In our series the longest recurrence after complete resection occurred at 13 years but Reddy et al. reported $20 \%$ of recurrences occurring after 10 years follow-up, including one case at 25 years 5 . Regardless of the presence of residual disease, we would advocate the indefinite scanning of those diagnosed at or before age 40. It must be highlighted that in all published series, the majority of cases with regrowth/recurrence will occur within 10 years of surgery.

Although extremely effective at preventing regrowth, we do not advocate routine postoperative radiotherapy for cases with residual adenoma, as half of cases will have been unnecessarily exposed to longer-term risks. Emerging interest in the use of the dopamine agonist, cabergoline, in preventing regrowth, with small, non-randomised studies (totalling approximately 100 cases) reporting regrowth rates of approximately $14 \%$ in those treated with cabergoline compared to $42 \%$ of those not treated ${ }^{28-33}$. In these studies, doses of cabergoline varied from $1-3 \mathrm{mg}$ weekly, with variable follow up between 6 months to 6 years. Given approximately half of cases with residual disease will regrow, half of whom require a second intervention, interest in cabergoline for prevention of regrowth will continue. Prospective randomised studies are required to address this clinical question.

The main limitations of our study are inherent to its retrospective nature. We were able to follow up $70 \%$ of the operated cohort. Some cases were inevitably lost to follow up or followed up by private practitioners, however this is common to most series. We analysed adenoma size by maximum adenoma diameter instead of volume. Recently it has been shown 
that volumetric measurement correlates with maximal adenoma diameter ${ }^{34}$. Currently this technique is not widely used clinically, but shows promise to calculate growth rates which may predict need for intervention ${ }^{35}$.

Regrowth/recurrence of NFPMA after surgery is more likely in the presence of residual disease and in those who are younger at time of presentation. Males with residual disease are at increased risk of regrowth. We advocate lifelong imaging for those diagnosed at $<41$ years of age, irrespective of the presence of residual disease. In most cases that have shown regrowth or recurrence, initial observation is possible, but MDT discussion should guide further management.

\section{Disclosure}

The authors report no conflict of interest concerning the materials or methods used in this study or the findings specified in this paper.

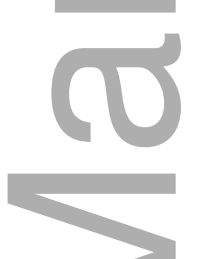

\section{References}

1. Lenders N, Ikeuchi, S, Russell, AW, et al. Longitudinal evaluation of the natural history of conservatively managed nonfunctioning pituitary adenomas. Clin Endocrinol (Oxf). 2016; 84(2):222-228.

2. Sheehan J, Lee, C-C, Bodach, ME, et al. Congress of neurological surgeons systematic review and evidence-based guideline for the management of patients with residual or recurrent nonfunctioning pituitary adenomas. Neurosurgery. 2016; 79(4):E539-E540.

3. Ziu M, Dunn, IF, Hess, C, et al. Congress of neurological surgeons systematic review and evidence-based guideline on posttreatment follow-up evaluation of patients with nonfunctioning pituitary adenomas. Neurosurgery. 2016; 79(4):E541-E543.

4. Grant FC. Surgical experience with tumors of the pituitary gland. J Am Med Assoc. 1948; 136(10):668-672.

5. Reddy R, Cudlip, S, Byrne, JV, et al. Can we ever stop imaging in surgically treated and radiotherapy-naive patients with non-functioning pituitary adenoma? Eur J Endocrinol. 2011; 165(5):739-744. 
6. Lee MH, Lee, JH, Seol, HJ, et al. Clinical concerns about recurrence of nonfunctioning pituitary adenoma. Brain Tumor Res Treat. 2016; 4(1):1-7.

7. O'sullivan EP, Woods, C, Glynn, N, et al. The natural history of surgically treated but radiotherapy - naïve nonfunctioning pituitary adenomas. Clin Endocrinol (Oxf). 2009; 71(5):709-714.

8. Ferrante E, Ferraroni, M, Castrignanò, T, et al. Non-functioning pituitary adenoma database: A useful resource to improve the clinical management of pituitary tumors. Eur $J$ Endocrinol. 2006; 155(6):823-829.

9. Ayuk J, Stewart, P. Mortality following pituitary radiotherapy. Pituitary. 2009; $12(1): 35-39$.

10. Alameda C, Lucas, T, Pineda, E, et al. Experience in management of 51 nonfunctioning pituitary adenomas: Indications for post-operative radiotherapy. J Endocrinol Invest. 2005; 28(3):18-22.

11. Turner H, Stratton, I, Byrne, J, et al. Audit of selected patients with non-functioning pituitary adenomas treated without irradiation-a follow-up study. Clin Endocrinol (Oxf). 1999; 51:281-284.

12. Bradley KM, Adams, CB, Potter, CP, et al. An audit of selected patients with nonfunctioning pituitary adenoma treated by transsphenoidal surgery without irradiation. Clin Endocrinol (Oxf). 1994; 41(5):655-659.

13. Soto-Ares G, Cortet-Rudelli, C, Assaker, R, et al. Mri protocol technique in the optimal therapeutic strategy of non-functioning pituitary adenomas. Eur J Endocrinol. 2002; 146(2):179-186.

14. Greenman Y, Ouaknine, G, Veshchev, I, et al. Postoperative surveillance of clinically nonfunctioning pituitary macroadenomas: Markers of tumour quiescence and regrowth. Clin Endocrinol $(O x f) .2003 ;$ 58(6):763-769.

15. Caputo C, Sutherland, T, Farish, S, et al. Gender differences in presentation and outcome of nonfunctioning pituitary macroadenomas. Clin Endocrinol (Oxf). 2013; 78(4):564-570.

16. De Witte O, Lonneville, S, Balériaux, D, et al. [non-functioning pituitary adenoma: Is there an interest to treat a residue after surgery?]. Rev Med Brux. 2010; 32(6):509-512. 17. Losa M, Mortini, P, Barzaghi, R, et al. Early results of surgery in patients with nonfunctioning pituitary adenoma and analysis of the risk of tumor recurrence. $J$ Neurosurg. 2008; 108(3):525-532. 
18. Chang EF, Zada, G, Kim, S, et al. Long-term recurrence and mortality after surgery and adjuvant radiotherapy for nonfunctional pituitary adenomas. J Neurosurg. 2008;

19. Dekkers O, Pereira, A, Roelfsema, F, et al. Observation alone after transsphenoidal surgery for nonfunctioning pituitary macroadenoma. J Clin Endocrinol Metab. 2006; 91(5):1796-1801.

20. Brochier S, Galland, F, Kujas, M, et al. Factors predicting relapse of nonfunctioning pituitary macroadenomas after neurosurgery: A study of 142 patients. Eur J Endocrinol. 2010; 163(2):193-200.

21. Park P, Chandler, WF, Barkan, AL, et al. The role of radiation therapy after surgical resection of nonfunctional pituitary macroadenomas. Neurosurgery. 2004; 55(1):100-107.

22. Bradley KJ, Wass, JA, Turner, HE. Non-functioning pituitary adenomas with positive immunoreactivity for acth behave more aggressively than acth immunonegative tumours but do not recur more frequently. Clin Endocrinol (Oxf). 2003; 58(1):59-64.

23. Jahangiri A, Wagner, JR, Pekmezci, M, et al. A comprehensive long-term retrospective analysis of silent corticotrophic adenomas vs hormone-negative adenomas. Neurosurgery. 2013; 73(1):8-17; discussion 17-18.

24. Del Basso De Caro M, Solari, D, Pagliuca, F, et al. Atypical pituitary adenomas: Clinical characteristics and role of ki-67 and p53 in prognostic and therapeutic evaluation. A series of 50 patients. Neurosurg Rev. 2017; 40(1):105-114.

25. Saeger W, Honegger, J, Theodoropoulou, M, et al. Clinical impact of the current who classification of pituitary adenomas. Endocr Pathol. 2016; 27(2):104-114.

26. Pal A, Capatina, C, Tenreiro, A, et al. Pituitary apoplexy in non - functioning pituitary adenomas: Long term follow up is important because of significant numbers of tumour recurrences. Clin Endocrinol (Oxf). 2011; 75(4):501-504.

27. Cortet-Rudelli C, Bonneville, J-F, Borson-Chazot, F, et al. Post-surgical management of non-functioning pituitary adenoma. Ann Endocrinol (Paris). 2015; 76(3):228-238.

28. Greenman Y, Cooper, O, Yaish, I, et al. Treatment of clinically nonfunctioning pituitary adenomas with dopamine agonists. Eur J Endocrinol. 2016; 175(1):63-72. 29. De Herder WW, Reijs, AE, Feelders, RA, et al. Dopamine agonist therapy of clinically non-functioning pituitary macroadenomas. Is there a role for $123 \mathrm{i}$-epidepride dopamine d2 receptor imaging? Eur J Endocrinol. 2006; 155(5):717-723.

30. Lohmann T, Trantakis, C, Biesold, M, et al. Minor tumour shrinkage in nonfunctioning pituitary adenomas by long-term treatment with the dopamine agonist cabergoline. Pituitary. 2001; 4(3):173-178.

This article is protected by copyright. All rights reserved 
31. Vieira Neto L, Wildemberg, LE, Moraes, AB, et al. Dopamine receptor subtype 2 expression profile in nonfunctioning pituitary adenomas and in vivo response to cabergoline therapy. Clin Endocrinol (Oxf). 2015; 82(5):739-746.

32. Garcia EC, Naves, LA, Silva, AO, et al. Short-term treatment with cabergoline can lead to tumor shrinkage in patients with nonfunctioning pituitary adenomas. Pituitary. 2013; 16(2):189-194.

33. Pivonello R, Ferone, D, De Herder, WW, et al. Dopamine receptor expression and function in corticotroph pituitary tumors. J Clin Endocrinol Metab. 2004; 89(5):2452-2462. 34. Davies BM, Carr, E, Soh, C, et al. Assessing size of pituitary adenomas: A comparison of qualitative and quantitative methods on mr. Acta Neurochir (Wien). 2016; 158(4):677-683.

35. Ratnasingam J, Lenders NF, Ong B, et al. Predictors for secondary intervention in surgically resected non-functioning pituitary adenoma. Procedings of the Endocrine Society (Abstract) 2016 SUN-479.

\section{Figures \& Tables}

Figure 1. Kaplan-Meier survival for regrowth/recurrence in those with and without residual disease.

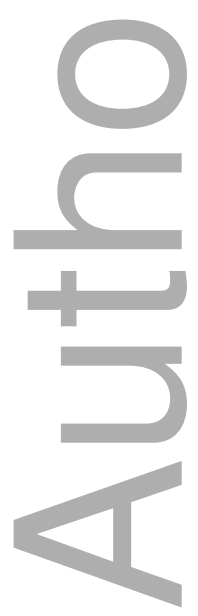




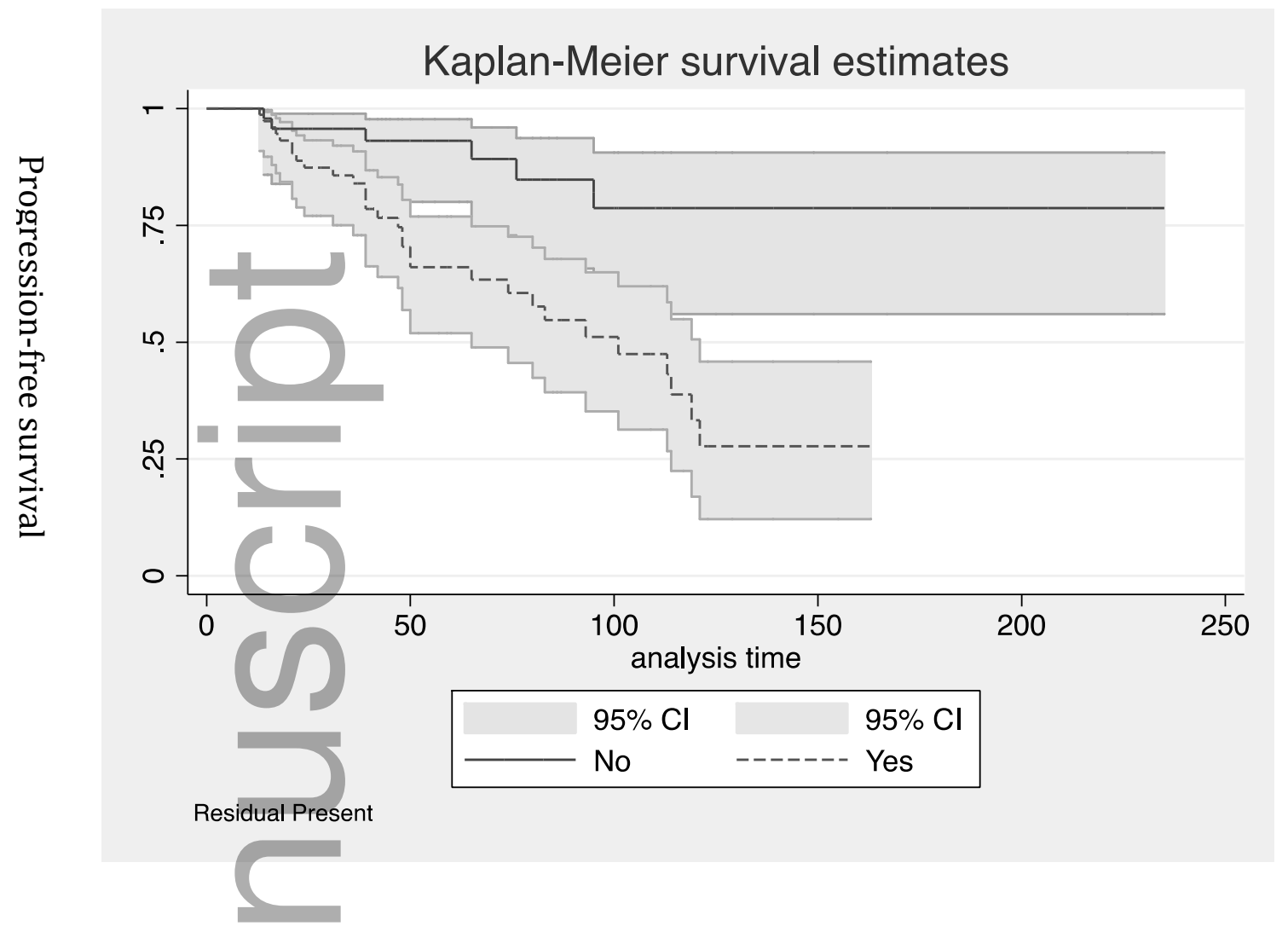

CI: Confidence interval

Analysis time in months

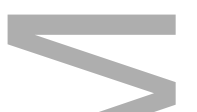

Figure 2. Kaplan-Meier survival for regrowth/recurrence by age.

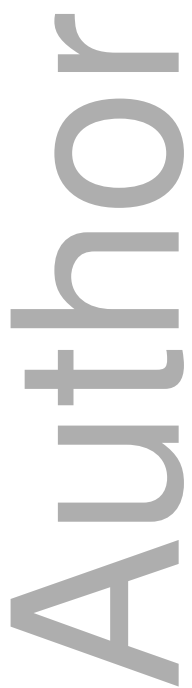




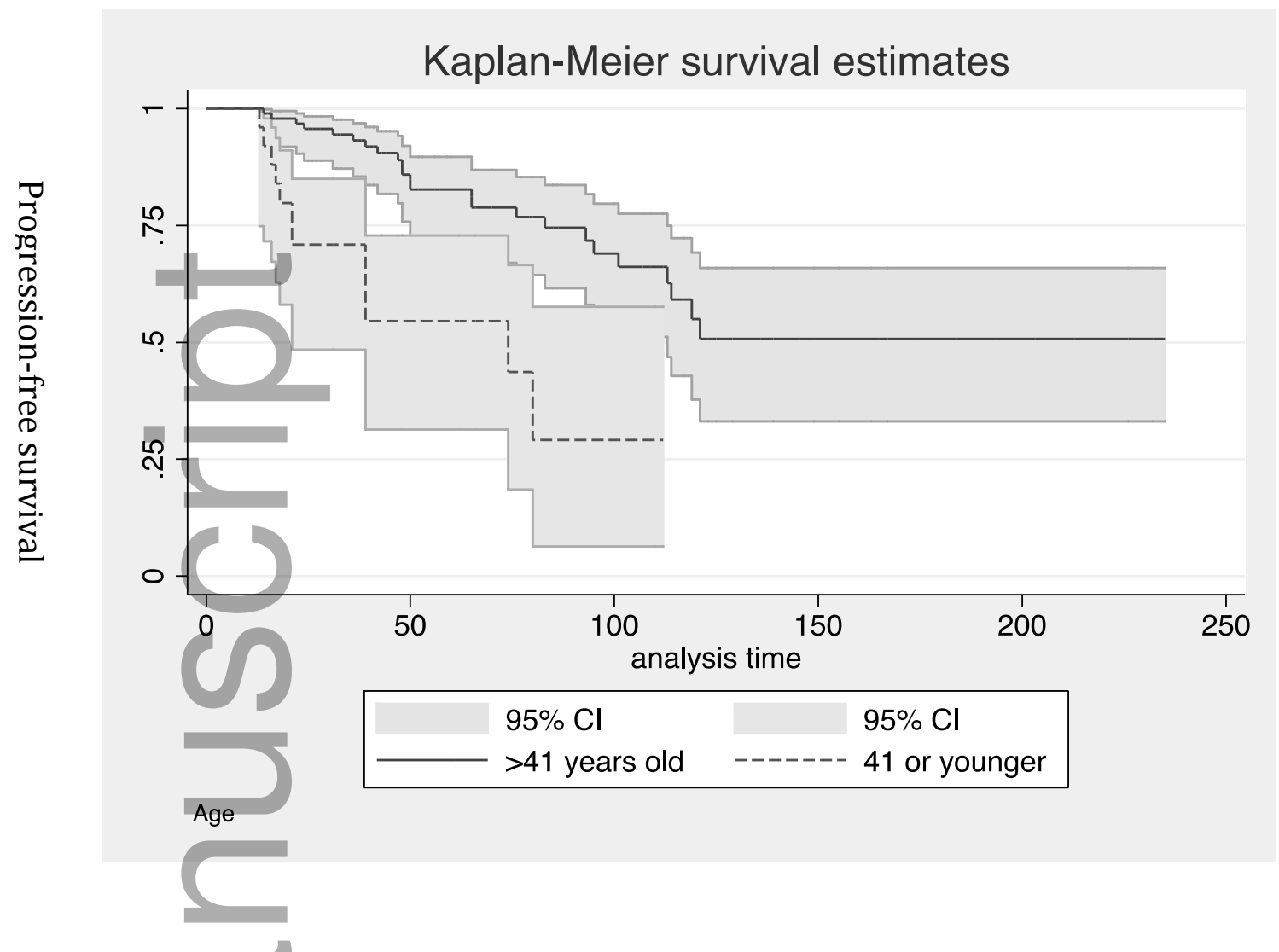

CI: Confidence interval

Analysis time in months

Table 1. Baseline Demographical Details

CSF: cerebrospinal fluid

DI: diabetes insipidus

IQR: interquartile range

$\%$ : percentage

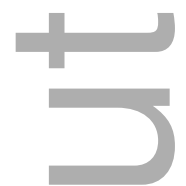

Table 2. Characteristics of those with Regrowth/recurrence

IQR: interquartile range

Table 3. Determinants of Regrowth/recurrence

IQR: interquartile range

This article is protected by copyright. All rights reserved 
Mm: millimeters

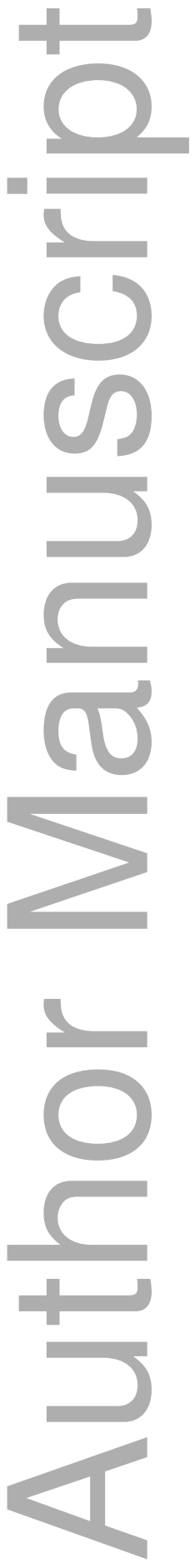

This article is protected by copyright. All rights reserved 
Table 1. Baseline Demographical Details

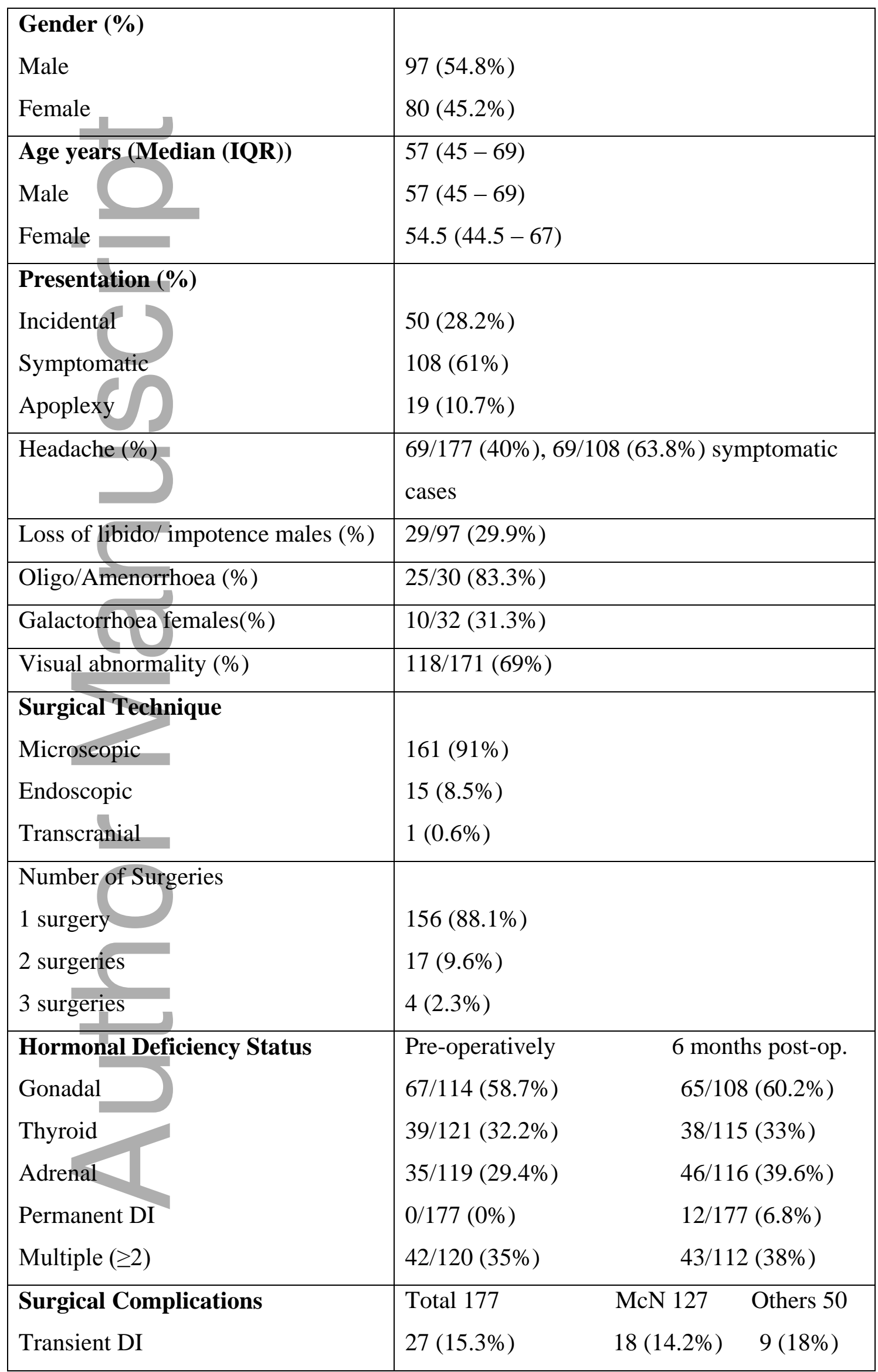

This article is protected by copyright. All rights reserved 


\begin{tabular}{|l|lll|}
\hline Permanent DI & $12(6.8 \%)$ & $6(4.7 \%)$ & $6(12 \%)$ \\
CSF leak & $8(4.5 \%)$ & $4(3.1 \%)$ & $4(8 \%)$ \\
SIADH & $14(8.0 \%)$ & $8(6.3 \%)$ & $6(12 \%)$ \\
Significant infection & $3(1.7 \%)$ & $1(0.8 \%)$ & $2(4 \%)$ \\
Significant bleeding & $2(1.1 \%)$ & $1(0.8 \%)$ & $1(2 \%)$ \\
Cardiac events & $2(1.1 \%)$ & $2(1.6 \%)$ & 0 \\
Other - retained nasal packs & $1(0.6 \%)$ & $1(0.8 \%)$ & 0 \\
Total cases with $\geq 1$ complications & $57(32.2 \%)$ & $38(29.9 \%)$ & $23(46 \%)$ \\
\hline Immunohistochemistry & & & \\
Null & $80 / 174(46.0 \%)$ & & \\
Mixed & $37 / 174(21.3 \%)$ & & \\
Pure LH/FSH & $28 / 174(16.1 \%)$ & & \\
Silent ACTH & $11 / 174(6.3 \%)$ & & \\
Necrotic & $8 / 174(4.6 \%)$ & & \\
TSH & $6 / 174(3.4 \%)$ & & \\
PRL & $3 / 174(1.7 \%)$ & & \\
GH & $1 / 174(0.6 \%)$ & & \\
\hline
\end{tabular}

CSF: cerebrospinal fluid

DI: diabetes insipidus

IQR: interquartile range

$\%$ : percentage

SIADH: syndrome of inappropriate anti diuretic hormone

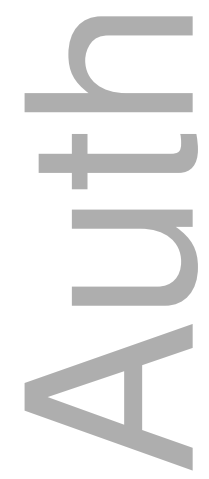


Table 2. Characteristics of those with Regrowth/ Recurrence

\begin{tabular}{|c|c|c|c|}
\hline נת & $\begin{array}{l}\text { Regrowth if } \\
\text { residual adenoma } \\
(\mathrm{N}=30)\end{array}$ & $\begin{array}{l}\text { Recurrence if no } \\
\text { residual adenoma } \\
(\mathrm{N}=6)\end{array}$ & P Value \\
\hline $\begin{array}{l}\text { Time to growth (months) } \\
\text { Median (IQR) }\end{array}$ & $42(24-84)$ & $48(12-96)$ & 0.7 \\
\hline $\begin{array}{l}\text { Progression Free Survival } \\
5 \text { years } \\
10 \text { years }\end{array}$ & $\begin{array}{l}67 \% \\
38 \%\end{array}$ & $\begin{array}{l}92 \% \\
77 \%\end{array}$ & $\begin{array}{l}0.07 \\
0.007\end{array}$ \\
\hline $\begin{array}{l}\text { Gender } \\
\text { Male } \\
\text { Female }\end{array}$ & $\begin{array}{l}21 / 40(52.5 \%) \\
9 / 35(25.7 \%)\end{array}$ & $\begin{array}{l}4 / 31(12.9 \%) \\
2 / 17(11.8 \%)\end{array}$ & $\begin{array}{l}1.00 \\
0.001 \\
0.47\end{array}$ \\
\hline $\begin{array}{l}\text { Recurrence / Regrowth requiring } \\
\text { intervention }\end{array}$ & $\begin{array}{l}17 / 76(22.3 \%) \\
17 / 30\end{array}$ & $\begin{array}{l}4 / 48(8.3 \%) \\
4 / 6\end{array}$ & 0.67 \\
\hline $\begin{array}{l}\text { Intervention } \\
\text { Observation } \\
\text { Intervention } \\
\text { Surgery alone } \\
\text { Radiotherapy alone } \\
\text { Surgery \& Radiotherapy }\end{array}$ & $\begin{array}{c}13 / 30(43.3 \%) \\
17 / 30(56.7 \%) \\
7(23.3 \%) \\
5(16.7 \%) \\
5(16.7 \%)\end{array}$ & $\begin{array}{c}2 / 6(33.3 \%) \\
4 / 6(66.7 \%) \\
0(0 \%) \\
3(50 \%) \\
1(16.7 \%)\end{array}$ & $1.00 *$ \\
\hline
\end{tabular}

IQR: interquartile range

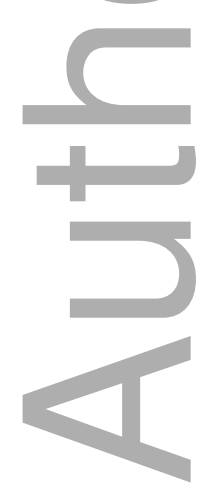


Table 3. Determinants of Regrowth/ Recurrence

\begin{tabular}{|c|c|c|c|}
\hline & $\begin{array}{l}\text { Regrowth/ } \\
\text { recurrence }(\mathrm{N}=36)\end{array}$ & $\begin{array}{l}\text { No regrowth } \\
(\mathrm{N}=87)\end{array}$ & P value \\
\hline $\begin{array}{l}\text { Residual } \\
\text { No residual }\end{array}$ & $\begin{array}{l}30 \\
6\end{array}$ & $\begin{array}{l}45 \\
42\end{array}$ & 0.0008 \\
\hline $\begin{array}{l}\text { Age at diagnosis Median (IQR) } \\
\text { Overall } \\
\text { Male } \\
\text { Female } \\
\text { Binary } \leq 41 ;>41\end{array}$ & $\begin{array}{l}50(39-62) \\
54(34-63) \\
47(39-63)\end{array}$ & $\begin{array}{l}57(46-67) \\
57(46-68) \\
57(44-67)\end{array}$ & 0.0001 \\
\hline $\begin{array}{l}\text { Adenoma size pre operatively } \\
\text { Median (IQR) }\end{array}$ & $30(23-36)$ & $26(20.5-33)$ & $0.05^{*}$ \\
\hline $\begin{array}{l}\text { Duration of follow up } \\
\text { Median (IQR) }\end{array}$ & $44.5(21.5,78)$ & $52(32,100)$ & \\
\hline $\begin{array}{l}\text { Gender } \\
\text { Male } \\
\text { Female }\end{array}$ & $\begin{array}{l}25 \\
11\end{array}$ & $\begin{array}{l}46 \\
41\end{array}$ & 0.2 \\
\hline $\begin{array}{l}\text { Location of residual adenoma } \\
\text { Intrasellar } \\
\text { Extrasellar } \\
\text { Cavernous sinus }\end{array}$ & $\begin{array}{l}10 \\
1 \\
18 \\
\end{array}$ & $\begin{array}{l}19 \\
5 \\
19 \\
\end{array}$ & 1.0 \\
\hline Apoplexy Cases & 2 & 11 & 0.3 \\
\hline $\begin{array}{l}\text { Immunohistochemistry } \\
\text { Null } \\
\text { Mixed } \\
\text { Pure LH/FSH } \\
\text { Silent ACTH } \\
\text { Other (Necrotic, TSH, PRL, } \\
\text { GH) }\end{array}$ & $\begin{array}{l}17 \\
9 \\
7 \\
3 \\
0\end{array}$ & $\begin{array}{l}38 \\
19 \\
12 \\
5 \\
13\end{array}$ & 0.76 \\
\hline
\end{tabular}

IQR: interquartile range

Mm: millimeters

This article is protected by copyright. All rights reserved 


\section{University Library}

\section{- M M I N E R VA \\ A gateway to Melbourne's research publications}

Minerva Access is the Institutional Repository of The University of Melbourne

Author/s:

Watts, AK;Easwaran, A;McNeill, P;Wang, YY;Inder, WJ;Caputo, C

Title:

Younger age is a risk factor for regrowth and recurrence of nonfunctioning pituitary macroadenomas: Results from a single Australian centre.

Date:

2017-09

Citation:

Watts, A. K., Easwaran, A., McNeill, P., Wang, Y. Y., Inder, W. J. \& Caputo, C. (2017). Younger age is a risk factor for regrowth and recurrence of nonfunctioning pituitary macroadenomas: Results from a single Australian centre.. Clin Endocrinol (Oxf), 87 (3), pp.264-271. https://doi.org/10.1111/cen.13365.

Persistent Link:

http://hdl.handle.net/11343/292967 